\title{
Emissions of Brominated Compounds and Polycyclic Aromatic Hydrocarbons during Pyrolysis of E-Waste Debrominated in Subcritical Water
}

\author{
Aurora Soler, Juan A. Conesa*, Nuria Ortuño \\ Department of Chemical Engineering, University of Alicante, P.O. Box 99, E-03080 Alicante \\ *Email: ja.conesa@ua.es
}

\begin{abstract}
Degradation of brominated flame retardants present in printed circuit boards (PCBs) was tested using subcritical water in a high pressure reactor. Debromination experiments were carried out in a batch stirred reactor at three different temperatures $\left(225{ }^{\circ} \mathrm{C}, 250^{\circ} \mathrm{C}\right.$ and $\left.275{ }^{\circ} \mathrm{C}\right)$ keeping a solid to liquid (S/L) ratio of PCB:water=1:5 during $180 \mathrm{~min}$. Results indicated that debromination efficiency was increased with temperature (18.5 to $63.6 \%$ of bromine present in the original PCB was removed). Thermal decomposition of the debrominated materials was studied and compared with that of the original PCB. Thermogravimetric analyses were performed at three different heating rates (5, 10 and $20 \mathrm{~K} \mathrm{~min}^{-1}$ ), studying both the pyrolysis (inert atmosphere) and combustion (in air). Pyrolysis runs of the debrominated materials were also performed in a quartz horizontal laboratory furnace at $850{ }^{\circ} \mathrm{C}$, in order to study the emission of pollutants. More than $99 \%$ of the bromine was emitted in the form of $\mathrm{HBr}$ and $\mathrm{Br}_{2}$. Emissions of polycyclic aromatic hydrocarbons (PAHs) and bromophenols (BrPhs) decreased with the increase in the treatment temperature; naphthalene $\left(10800-18300 \mathrm{mg} \mathrm{kg}^{-1}\right.$ original sample) and monobrominated phenols (12.8 - $16.9 \mathrm{mg} \mathrm{kg}^{-1}$ original sample) were the most abundant compounds.
\end{abstract}

Keywords: Debromination, Printed circuit board (PCB), Thermogravimetric analysis (TGA), Pyrolysis, Bromophenols, Hydrothermal treatment 


\section{INTRODUCTION}

Waste from electrical and electronic equipment (WEEE) is defined as waste originating from electrical and electronic equipment which has reached end-of-life, including all components, subassemblies and consumables which are part of the product at the time of discarding. Electrical and electronic equipment needs electric current to work properly with a voltage rating lower than $1000 \mathrm{~V}$ for alternating current and 1,500 V for direct current (European Council, 2004).

In recent years, electrical and electronic equipment consumption has grown rapidly worldwide because these appliances become quickly obsolete due to fast technological innovations. Consequently, WEEE generation has increased significantly; e-wastes are estimated to grow at a rate 3 times higher than the rest of municipal solid wastes (MSW). More specifically, the amount of printed circuit boards (PCBs) is estimated to be increasing at a rate of 5-10\% annually (Jaiswal et al., 2015). As a result, every year, twenty to fifty million tons of WEEE are generated in the world (Herat, 2008). In the light of these figures, it is not difficult to understand the importance of recycling this type of wastes.

Recycling WEEE is important, not only to reduce the amount of waste requiring treatment, but also to encourage the recovery of raw materials contained in this kind of equipment, such as plastics, base metals (copper, tin), and precious metals (gold, silver, platinum), as well as to eliminate responsibly its environmentally dangerous compounds such as brominated flame retardants and heavy metals (Buekens and Yang, 2014). WEEE can be a serious threat to human health (Leung et al., 2008) and the environment (Owens et al., 2007) if they are not properly treated. In this way, the Directive on Waste Electrical and Electronic Equipment aims to promote the recycling, reuse and recovery of these types of wastes (European Commission, 2012). 
The metallic materials recovered are considered the most valuable part of the WEEE. These metals can become part of new industrial processes. As far as plastic materials are concerned, until very recently, they were considered low value products and accumulated in landfills. However, the plastic fraction is now considered more valuable than before, because it can be used towards material, chemical or energy recovery. Therefore, the recycling of WEEE is important from environmental, occupational and economic perspectives, and it can also help to mitigate the exhaustion of finite natural resources.

Estimations suggest that PCBs constitute approximately 6\% of the total weight of WEEE (Das et al., 2009), and represent one of its most complex constituents. Waste PCBs mainly originate from mobile phones, computers and televisions. In particular, PCBs are especially problematic to recycle because of the heterogeneous mix of organic material, metals and fiberglass.

The recycling process of PCBs is divided into three stages: disassembly, separation of metallic and non-metallic fractions by using mechanical or chemical techniques, and finally recycling of both fractions separately. The metallic fraction takes up about $30 \%$ of the weight content of PCBs and consists of copper, tin, lead, iron, nickel and noble metals (Goosey and Kellner, 2003), whereas the rest is the non-metallic fraction that consists of thermosetting resins, reinforcing materials, brominated flame retardants (BFRs) and other additives (Guo et al., 2009). The recycling rate in Europe barely exceeds 15\% (Goosey and Kellner, 2002).

PCBs contain between 5 to $15 \%$ of BFRs that are added in order to inhibit the combustion process in case of fire, limiting the amount of heat released (Chien et al., 2000). BFRs are the most used today because they have the best cost-benefit ratio. There are more than 75 types of BFRs (Birnbaum and Staskal, 2004). However, the most used BFRs are polybrominated biphenyls (PBB), tetrabromobisphenol A (TBBPA), hexabromocyclododecanes (HBCDD) and polybrominated diphenyl ethers (PBDE). TBBPA is the most widely used brominated flame retardant worldwide. In 
2004, the production of TBBPA was of 170,000 tons (Malkoske et al., 2016), representing around $60 \%$ of total BFRs production. BFRs are prone to bioaccumulate in humans producing undesired effects on health. In addition, severe problems of environmental pollution can occur if PCBs are not correctly treated, since BFRs can be leached out in landfills (Zhou et al., 2013) or cause the formation of toxic substances such as polybrominated dibenzo-p-dioxins/furans (PBDD/Fs) during combustion (Sakai et al., 2001). Altarawneh and Dlugogorski (2014b) observed that degradation of BFRs into brominated benzene and phenol rings contributes to the production of PBDD/Fs. Altarawneh and Dlugogorski (2015) also studied the formation of PBDFs during the oxidation of PBB and concluded that this practise generated high yields of toxic PBDFs. The development of removal methods of BFRs from WEEE has thus become more relevant.

The removal of bromine present in the polymeric matrix using supercritical or near supercritical fluids is gaining importance because of excellent debromination efficiency. The use of fluids in such conditions is justified by the fact that extraction is much faster and more efficient than when using liquid solvents, because low viscosity of supercritical fluids favors mass transfer phenomena and penetrability into the pores of the sample matrix. Onwudili and Williams (2009) used alkaline supercritical water to degrade several brominated flame-retarded plastics obtaining exceptional efficiency of debromination and a high potential to produce bromine-free oils. Brebu et al. (2006) reached a 90\% debromination of brominated high impact polystyrene under hydrothermal conditions at $300{ }^{\circ} \mathrm{C}$. Xing and Zhang (2013) studied the degradation of PCBs in supercritical water achieving a maximum removal of $97.8 \%$ of the bromine with a S/L ratio equal to $1: 4 \mathrm{~g} \mathrm{~mL}^{-1}$ at $400{ }^{\circ} \mathrm{C}$ for 120 min. Wath et al. (2015) used two organic solvents (N-methyl-2-pyrrolidone (NMP) and dimethyl sulfoxide (DMSO)) as supercritical fluids for degradation of waste PCBs, obtaining better results for the debromination with NMP. Additionally, Wang and Zhang (2012) showed the excellent efficiencies obtained using different supercritical fluids (water (97.6\%) > methanol (69.2\%) > 
isopropanol $(63.6 \%)>$ acetone (46.8\%)) for the debromination of computer housing plastic at $400{ }^{\circ} \mathrm{C}$ for 60 minutes.

The objectives of this study are as follows: (1) to evaluate the debromination efficiency of subcritical water treatments on PCBs; (2) to study the thermal decomposition of the different debrominated wastes obtained by thermogravimetry; and (3) to carry out a comparison of pollutant emissions during the pyrolysis of PCBs before and after the debromination process, taking special care with brominated pollutants.

\section{MATERIALS AND METHODS}

\subsection{Materials}

There are two types of PCBs depending on the materials employed: paper-based phenolic resin PCBs and fiberglass-based epoxy PCBs. Currently, fiberglass-based epoxy PCBs are the most used because they present good mechanical resistance and insulation, as well as being relatively inexpensive.

The National Electrical Manufacturers Association (NEMA) is an organization that is primarily concerned with electrical safety and classification of different degrees (FR1 to FR5) of materials utilized in the electric field, providing descriptions of product flammability and high-temperature stability. FR-4 is the electrical/mechanical grade assigned to glass-reinforced epoxy laminate sheets, tubes, rods and PCBs most widely in use today. FR-4 is characterised by high flexural, impact and bond strength at room temperatures. In addition, it retains good electrical properties under dry and humid conditions. It is used in the electrical industry and anywhere a high strength electrical insulator in humid or dry conditions is needed (NEMA, 2011).

In this study, the PCBs used were metal free FR-4 supplied by CISA (Circuitos Impresos S.A, Spain), consisting in a woven fiberglass cloth-based epoxy resin flame retardant. FR-4 PCBs typically employ TBBPA as BFR, and this has been confirmed by Raman spectroscopy. Figure SM1 of the Supplementary Material shows the Raman spectra obtained from PCB and TBBPA. As can be 
observed, there are two distinctive bands from 100 to $300 \mathrm{~cm}-1$ which are typical of TBBPA (O'Grady et al., 2001; Zheng et al., 2001; Kikuchi et al., 2004; Taurino et al., 2010).

The FR-4 PCBs were manually cut into $2 \mathrm{~cm} \times 2 \mathrm{~cm}$ pieces using pliers and were crushed to fine dust using a vibratory disc mill RETSCH RS 200. Then, FR-4 PCBs were characterized. Elemental analysis (25.61 wt.\% C, 2.22 wt.\% H, 0.91 wt.\% N and 14.60 wt.\% O) was carried out in a Thermo Finnigan Flash 1112 Series Elemental Analyzer. The ash content was measured following the UNEEN-14775:2009 (ECS, 2010) at $550{ }^{\circ} \mathrm{C}$, and was 56.67 wt.\%. The concentrations of bromine and chlorine were measured using the US EPA Methods 5050 (US EPA, 1994b) and 9056A (US EPA, 2000b) by oxygen combustion bomb-ion chromatography (Dionex DX-500), the average values of two duplicates being 3.24 wt.\% for bromine and 0.067 wt.\% for chlorine, which is much lower than the bromine content, as usual for this kind of material.

\subsection{Subcritical water treatment}

The process of debromination, using water as a subcritical fluid, was carried out in a high-pressure batch stirred reactor (volume of $1000 \mathrm{~mL}$ ). This high-pressure reactor belongs to the FCF series of Zhengzhou Keda Machinery and Instrument Equipment Co. Ltd. It is constructed in 304 stainless steel. Maximum working pressure is $9.8 \mathrm{MPa}$ and the maximum temperature is $350{ }^{\circ} \mathrm{C}$.

The parameters controlling debromination efficiency are: temperature, solid/liquid (S/L) ratio and residence time. In this work study, debromination runs were carried out at three different temperatures $\left(225{ }^{\circ} \mathrm{C}, 250{ }^{\circ} \mathrm{C}\right.$ and $275^{\circ} \mathrm{C}$ ) with the $\mathrm{S} / \mathrm{L}$ ratio equal to $1: 5 \mathrm{~g} \mathrm{~mL}^{-1}$ during $180 \mathrm{~min}$, so $\mathrm{S} / \mathrm{L}$ ratio and residence time were not limiting factors in the process, according to the optimal conditions reported by Xing and Zhang (2013). In this way, the pressure reached in the container corresponded to the vapor pressure of water at each temperature, approximately 2.5, 4.0 and 6.0 MPa. About $100 \mathrm{~g}$ of the PCB sample were introduced into the reactor at each run. 
A temperature higher than $200{ }^{\circ} \mathrm{C}$ was necessary, the debromination process being practically nonexistent under this temperature (Xing and Zhang, 2013) because energy provided by the system is not enough to break the chemical bonds of the resin.

The solid residue obtained was separated by filtration and was dried at room temperature for $48 \mathrm{~h}$. The bromine content of debrominated wastes was analyzed as explained above for the original FR-4 PCB sample. Water collected from the reaction chamber was also analyzed for bromine by ion chromatography in order to calculate the bromine balance along the runs.

\subsection{Thermo-gravimetric analysis (TGA)}

Thermogravimetric runs of original PCB and debrominated wastes were carried out on a Mettler Toledo TGA/SDTA851e/SF/1100 Thermal Gravimetric Analyzer. The decomposition temperatures were measured under dynamic conditions in combustion and pyrolysis with a total flow rate of 100 $\mathrm{mL} \min ^{-1}$. Dynamic runs were performed at heating rates of 5,10 and $20 \mathrm{~K} \mathrm{~min}{ }^{-1}$ for each atmosphere, from room temperature up to $1173 \mathrm{~K}$. For each run $10 \pm 0.3 \mathrm{mg}$ of the sample were used.

\subsection{Furnace for pyrolysis runs}

Pyrolysis was conducted at $850{ }^{\circ} \mathrm{C}$ with original PCB and debrominated wastes, using a tubular quartz reactor located inside a horizontal laboratory furnace. This equipment has been previously described in detail (Aracil et al., 2005; Moltó et al., 2011). For each run, nitrogen was introduced at a

constant flow of $300 \mathrm{~mL} \mathrm{~min}^{-1}$ in parallel to the sample movement. The temperature of $850{ }^{\circ} \mathrm{C}$ was used because this is the temperature reached in the post-combustion zone in combustion treatment plants (European Commission, 2000).

The sample mass in each experiment was $100 \pm 5 \mathrm{mg}$. Once the set temperature had been reached, the sample was introduced in the reactor at a constant speed of $0.5 \mathrm{~mm} \mathrm{~s}^{-1}$ and maintained inside the reactor for $25 \mathrm{~min}$, while the compounds leaving the reactor were sampled for subsequent analysis. 


\subsubsection{Analysis of hydrogen halides and halogen gases}

The determination of the emissions of inorganic bromine during pyrolysis runs was performed by passing the gases through four impingers. The two first impingers contained $0.1 \mathrm{~N}$ sulfuric acid solution and the others contained $0.1 \mathrm{~N}$ sodium hydroxide solution, following the US EPA method 26 (US EPA, 1994a). The hydrogen halides were solubilized in the acid solution, whereas the halogens passed through to the alkaline solution where they were hydrolyzed to form a proton $\left(\mathrm{H}^{+}\right)$, the halide ion and the hypohalous acid. Following the method's recommendations, sodium thiosulfate was added in excess to the alkaline solution to assure reaction with the hypohalous acid, to form a second halide ion such that two halides ions are formed for each molecule of halogen gas. These solutions were analyzed by ion chromatography.

\subsubsection{Analysis of semivolatile compounds}

The generated semivolatile compounds were collected using Amberlite XAD-2 resin as adsorbent (Supelco, Bellefonte, USA), that was placed at the exit of the furnace during the entire run. To analyze the concentration of polycyclic aromatic hydrocarbons (PAHs) and bromophenols (BrPhs) in the samples, two internal standards $(10 \mu \mathrm{L}$ of deuterated PAH Mix 26 from Dr. EhrenstorferSchäfers, Germany, and $100 \mu \mathrm{L}$ of ${ }^{13} \mathrm{C}$ mass-labelled bromophenol solution (MBRPS) from Wellington Laboratories, USA) were added to the resin. The resin was then extracted using a mixture of dichloromethane-acetone (1:1) by Accelerated Solvent Extraction (ASE-100 Dionex-Thermo Fisher Scientific, USA) following the US EPA method 3545A (US EPA, 2000a). The extract was concentrated in a rotary evaporator and with a moderate stream of nitrogen up to $1.5 \mathrm{~mL}$. Finally, 3 $\mu \mathrm{L}$ of a solution of $2000 \mu \mathrm{g} \mathrm{mL} \mathrm{L}^{-1}$ of anthracene- $\mathrm{d}_{10}$ (AccuStandard, USA) was added as a recovery standard.

The identification and quantification of the 16 priority PAHs established by the U.S. EPA (US EPA, 1998) were performed according to the US EPA method 8270D (US EPA, 2007). The analysis was 
carried out in a GC-MS (Agilent GC 6890N/Agilent MS 5976N, Agilent Technologies, USA) in SCAN mode with an Agilent HP-5 MS capillary column (30 m x 0.25 mm i.d. x $0.25 \mu \mathrm{m}$ ). BrPhs were analyzed with the same equipment but in SIR mode (Selected Ion Recording) and the identification of each isomer was confirmed by calculating the ratio between the areas of the primary and secondary ions. The 16 priority PAHs and BrPhs were quantified by internal standard calibration. The rest of the semivolatile compounds were identified comparing the mass spectrum of each compound with that of the NIST database, guaranteeing a confidence rate above $80 \%$, and semi-quantified interpolating between the response factors from the two nearest deuterated standards.

\section{RESULTS AND DISCUSSION}

\subsection{Debromination of PCBs}

The process took place at the water vapor pressure at the corresponding temperature (approximately 2.5 MPa at $225^{\circ} \mathrm{C}, 4.0 \mathrm{MPa}$ at $250^{\circ} \mathrm{C}$ and $6.0 \mathrm{MPa}_{-}$at $275^{\circ} \mathrm{C}$ ) with a partial degradation of the original PCB. The runs were performed with $100 \mathrm{~g}$ of PCB and gave a solid yield of 95.7, 85.3 and 83.9 wt.\% at 225,250 and $275^{\circ} \mathrm{C}$, respectively.

Concentration of bromine in the solid residue were 2.76, 2.29 and 1.41 wt.\% for the runs at 225, 250 and $275{ }^{\circ} \mathrm{C}$, respectively, analyzed by ion chromatography. Water collected from the reaction chamber was also analyzed for bromine ions, producing a closed bromine balance with a deviation below $8 \%$.

Results showed that the concentration of bromine in the waste decreased with the increase of process temperature, which in turn indicates that the debromination treatment was more effective because a higher amount of bromine present in the PCB was transferred to water. Debromination efficiency can be calculated using the following equation:

Debromination efficiency $=\left(\mathrm{M}_{\mathrm{Br} \text { i }}-\mathrm{M}_{\mathrm{Brf}}\right) \cdot 100 / \mathrm{M}_{\mathrm{Br} \text { i }}$ 
where $\mathrm{M}_{\mathrm{Br}}$ i is the initial mass of bromine in PCBs and $\mathrm{M}_{\mathrm{Br} f}$ is the mass of bromine in the solid residue.

A total of $18.5 \%$ of bromine present in FR-4 PCBs was removed when the debromination treatment was carried out at $225{ }^{\circ} \mathrm{C}$, then $39.6 \%$ was removed at $250{ }^{\circ} \mathrm{C}$ and finally $63.6 \%$ at $275{ }^{\circ} \mathrm{C}$. These results showed that the treatment at high temperature and pressure could provide enough energy to break the chemical bonds of the resin, favoring the decomposition of the brominated epoxy resin. Possible degradation pathways of brominated epoxy resin at different temperatures have been proposed by Yin et al. (2011). The most important debromination results are summarized in Table 1.

(Table 1)

\subsection{Thermogravimetric study}

Pyrolysis (in nitrogen) and combustion (in air) runs were carried out in order to characterize every solid material in this study. Dynamic runs at three different heating rates $\left(5,10\right.$ and $\left.20{ }^{\circ} \mathrm{C} \min ^{-1}\right)$ were performed for each material, at room temperature up to $900{ }^{\circ} \mathrm{C}$. Three heating rates were used to obtain a complete characterization. Figure 1 presents the results on the decomposition of original PCB and debrominated materials prepared by treatment at 225, 250 and $275{ }^{\circ} \mathrm{C}$, in nitrogen atmosphere. Figure 2 presents the results for combustion in air.

As expected, for all materials, mass loss curves move to the right (towards higher temperatures) when increasing the heating rate. This has been observed by many authors who have put forward a variety of explanations. However, taking kinetic law into consideration alone should be enough to explain this phenomenon (Caballero and Conesa, 2005; Conesa and Rey, 2015; Conesa and Soler, 2016). On the other hand, the effect of oxygen presence is similar for all materials, accelerating thermal decomposition (i.e. the curve is observed at lower temperatures compared to the pyrolysis) and producing oxidation of the final pyrolytic residue. In a previous study (Ortuño et al., 2013), it was shown that the decomposition of PCBs in the presence of oxygen leads to a weight increase, due 
to the combination of oxygen with the metal contained in the samples. In our experiments, a weight increase was not observed because the PCBs used consisted only of laminates, with no metallic layers or electrical components.

(Figures 1 and 2)

Figure 3 presents a comparison of the decomposition of all materials at $5{ }^{\circ} \mathrm{C} \mathrm{min}^{-1}$, in order to discuss the decomposition details. As can be seen, the total mass loss of debrominated materials decreases if debromination temperature increases. This is an expected behavior, as a more severe treatment will produce a more degraded material with a higher percentage of inert materials. It is also clear that the materials previously treated at higher debromination temperatures begin to decompose at lower temperatures, indicating that the polymeric matrix of the PCB is ever more degraded when debromination temperature increases. This effect is more evident in the TG runs performed in the presence of air.

(Figure 3)

Figure SM2 of the Supplementary Material shows the results of the elemental analysis of the solids, where it can be seen that the percentage of carbon, nitrogen and hydrogen decreases by increasing the treatment temperature, denoting that the inorganic fraction remains unaltered.

\subsection{Pollutant emissions}

All emission results refer to the amount of original PCB introduced into the high-pressure reactor at each run.

\subsubsection{Hydrogen halides and halogens}

The emissions of inorganic bromine are shown in Table 2. Emissions significantly decrease when increasing the temperature of the treatment. The solid residue, which was subjected to debromination at $275^{\circ} \mathrm{C}$, emits $60.8 \%$ less inorganic bromine than the original PCB. For all materials, the emission 
factors of $\mathrm{HBr}$ are higher than the ones for $\mathrm{Br}_{2}$. Altarawneh and Dlugogorski (2014a) also found that the major product generated in the thermal decomposition of TBBPA was HBr. The total yield of $\mathrm{HBr}+\mathrm{Br}_{2}$ with the original $\mathrm{PCB}$ is similar as it is, only slightly higher than that detected in previous studies (Ortuño et al., 2014a).

\section{(Table 2)}

\subsubsection{PAHs and other semivolatile compounds}

Figure 4 shows the results of emissions of the 16 priority PAHs during pyrolysis at $850^{\circ} \mathrm{C}$ in the horizontal reactor. Data is also available in Table SM1 of Supplementary Material. As can be seen, compounds profiles were similar for all samples. The most abundant compounds were naphthalene, followed by acenaphtylene, phenanthrene and fluorene. Results are compatible with previous studies where yields reached their maximum in pyrolysis at high temperature $\left(850^{\circ} \mathrm{C}\right)$ because pyrolytic reactions are the primary source of PAH formation (Thomas and Wornat, 2008) and the naphthalene was clearly the most abundant PAH formed in the thermal degradation of different materials (Conesa et al., 2009).

The potential for the formation of such PAHs seems to have effectively decreased during the subcritical water treatment, since the emission factors decreased when increasing the temperature of the pre-treatment. Emissions from the original PCB were similar, being only, slightly higher than those detected previously in the pyrolysis at $850{ }^{\circ} \mathrm{C}$ of waste PCBs after removal of metal (Ortuño et al., 2014a) and electronic circuits from mobile phones (Moltó et al., 2011).

\section{(Figure 4)}

Other semivolatile compounds were also detected. Figure 5 shows main results, where a similar trend is found for all samples. Semivolatile compounds are produced from incomplete combustion, and lower temperatures favor their formation (Conesa et al., 2009). Therefore, emissions of these compounds were much lower than PAH emissions because the pyrolysis was carried out at high 
temperature. GC-MS results showed that semivolatile compound emissions were mainly constituted by complex organic polyaromatic compounds of 8-20 carbon atoms, whose molecular weights ranged from 104 to 252. In order of abundance, phenol, styrene and benzofuran were the most abundant products detected in all runs. This is in accordance with results obtained by Ortuño et al. (2014a). In addition to these, some of the most important degradation products consisted in nonsubstituted polyaromatic compounds (i.e. biphenyl and triphenylene), as well as methylated benzofurans and naphthalenes. The emitted phenol compound had the highest yield in the PCBs pyrolysis (Williams, 2010) because it is present in the epoxy resin.

Furthermore, emission of almost all detected compounds was reduced in samples having undergone the subcritical water treatment, emission being more effective when the treatment temperature increases, as observed for PAHs.

(Figure 5)

\subsubsection{Brominated pollutants}

Due to the abundance of bromine in electronic waste, a more detailed search for brominated compounds was carried out within the pyrolytic semivolatile compounds. Three compounds where detected during the decomposition of all samples, as shown in Table 3: 9-bromo-9H-fluorene, bromobenzene and 5-bromobenzofuran. Worthy of note is that the emission of these compounds decreased with an increase of the debromination temperature.

Bromobenzene was previously detected in higher proportions during the pyrolysis of electronic circuits from mobile phones (with no elimination of the metallic fraction) (Moltó et al., 2011). However, another previous study (Ortuño et al., 2014b) shows that the amount of bromobenzene during the pyrolysis for the metal-free PCBs was 10 times higher than that observed for all PCBs. Therefore, the presence of metals does not seem to have a determining effect on the formation of these types of compounds, which is probably more dependent on operating conditions (e.g. temperature, atmosphere, residence time, etc.). 
It can also be observed that the amount of bromobenzene, 5-bromobenzofuran and 9-bromo-9Hfluorene emitted is higher for the debrominated samples than for the original PCB. When the TBBPA containing resin is submitted to high temperatures, such as $850{ }^{\circ} \mathrm{C}$ in the pyrolysis runs, the flame retardant releases bromine radicals which react with $\mathrm{H} \cdot$ and $\mathrm{OH} \cdot$ radicals, removing them from the gas phase of the flame. In our opinion, these are the predominant reactions for the original PCB sample, which emitted the highest amount of $\mathrm{HBr}$ and $\mathrm{Br}_{2}$, and a smaller amount of the other brominated compounds. In the case of the debrominated solid residues, a high amount of $\mathrm{HBr}$ and $\mathrm{Br}$ was generated, but it was lower than for the original PCB, whereas the proportion of other brominated compounds increased. It seems that the debromination procedure converts part of the initial brominated flame retardant from the resin into other Br-containing compounds, affecting the emission pattern of these compounds, such as bromobenzene, 5-bromobenzofuran and 9-bromo-9Hfluorene.

(Table 3)

Table 3 also shows the total amount of brominated phenols (BrPhs) detected in the pyrolysis runs carried out at $850^{\circ} \mathrm{C}$. As can be seen, the total yields of $\mathrm{BrPhs}$ decrease with the increase of debromination temperature resulting in $14.7 \mathrm{mg} \mathrm{kg}^{-1}$ for the solid residue obtained at $275^{\circ} \mathrm{C}, 18.0 \mathrm{mg}$ $\mathrm{kg}^{-1}$ for the solid residue obtained at $250^{\circ} \mathrm{C}$ and $20.0 \mathrm{mg} \mathrm{kg}^{-1}$ for the one obtained at $225^{\circ} \mathrm{C}$. Total yields of BrPhs of solid residues were all lower than the total yield from the original PCB (25.8 mg $\mathrm{kg}^{-1}$ ). These results show that treatment at high temperature and pressure could, to some extent, reduce the emissions of brominated compounds in thermal treatments. In previous studies (Ortuño et al., 2014a), the emission of BrPhs in pyrolysis at $850{ }^{\circ} \mathrm{C}$ of PCB waste was much higher, at around $800 \mathrm{mg} \mathrm{kg}^{-1}$; this fact could also be related to the presence of more $\mathrm{OH}^{-}$groups, due to previous treatment with an aqueous solution of $\mathrm{HCl}$ and $\mathrm{H}_{2} \mathrm{O}_{2}$, that was carried out to remove the metal fraction and could have favored the bromination of phenol. 
Table 3 shows the detail of the BrPh congeners detected in each run. For the solid residues, monoand dibrominated phenols were the most abundant products, particularly those with bromine in the positions 2-, 3-+4- (coeluted) and 2,6-. For the original PCB, a clear predominance of mono-, tri- and tetrabrominated phenols was observed, particularly those with bromine in the positions 2-, 3-+4(coeluted), 3,4,5- and 2,3,4,5-+2,3,4,6- (coeluted). In all cases, 2- $\mathrm{BrPh}$ was the most abundant compound, followed by 3-+4-BrPh. This is compatible with the formation patterns observed for emissions from the thermal decomposition of PCBs waste (Ortuño et al., 2014a) and tetrabromobisphenol A (Ortuño et al., 2014c; Saeed et al., 2016).

The low amount of 2,4,6-BrPh detected seems to support the most recent findings, which suggest that the previously proposed fission of the isopropylidene linkage (Barontini et al., 2004) via bromine addition, appears to be of minor importance (Altarawneh and Dlugogorski, 2014a).

\subsubsection{Bromine balance}

Once the emissions of brominated pollutants were evaluated, the balance of inorganic bromine was proved. Table 4 shows results on the mass balance of bromine for each material. All mass balances are considered acceptable. On the one hand, the emitted bromine balance for the original PCB is closed with a deviation of $4 \%$. Furthermore, bromine emitted during pyrolysis at $850{ }^{\circ} \mathrm{C}$ accounted for $85 \%, 97 \%$ and $94 \%$ of the initial bromine for the samples debrominated at $225^{\circ} \mathrm{C}, 250^{\circ} \mathrm{C}$ and $275^{\circ} \mathrm{C}$, respectively. In all cases, more than $99 \%$ of bromine was emitted in the form of inorganic bromine ( $\mathrm{HBr}$ and $\left.\mathrm{Br}_{2}\right)$.

(Table 4)

\section{Conclusions}

The results of this study show that subcritical water treatment was an efficient approach for debromination of PCBs waste. Debromination efficiency increased with the increase of process 
temperature. As a result, the maximum debromination rate of $63.6 \%$ was obtained at $275^{\circ} \mathrm{C}$. Most of the bromine was retained in the water.

With respect to the thermogravimetric study, the total mass loss of debrominated materials decreased when the debromination temperature increased, because amounts of the partially degraded polymeric base of the FR-4 PCBs were removed during debromination treatment, leading to a material with a higher percentage of inert materials.

When the samples were subjected to pyrolysis at $850{ }^{\circ} \mathrm{C}$, more than $99 \%$ of bromine was emitted in the form of $\mathrm{HBr}$. The emissions of $\mathrm{PAHs}$ and $\mathrm{BrPhs}$ decreased with the increase of treatment temperature and total yields originating from the decomposition of the debrominated materials were lower than the total yield from the FR-4 PCBs. In all cases, 2-BrPh was the most abundant compound, followed by 3-+4-BrPh. These results show that the subcritical water treatment could reduce the emissions of brominated compounds in subsequent thermal treatments of this kind of electric and electronic waste.

\section{AKNOWLEDGEMENTS}

Support for this work was provided by the CTQ2016-76608-R project from the Ministry of Economy and Competitiveness (Spain) and the PROMETEOII/2014/007 project from the Valencian Community Government (Spain).

\section{REFERENCES}

Altarawneh, M., Dlugogorski, B.Z., 2014a. Mechanism of thermal decomposition of tetrabromobisphenol a (TBBA). J. Phys. Chem. A 118, 9338-9346.

Altarawneh, M., Dlugogorski, B.Z., 2014b. Thermal Decomposition of 1,2-Bis(2,4,6tribromophenoxy)ethane (BTBPE), a Novel Brominated Flame Retardant. Environ. Sci. Technol. 48, 14335-14343.

Altarawneh, M., Dlugogorski, B.Z., 2015. Formation of polybrominated dibenzofurans from polybrominated biphenyls. Chemosphere 119, 1048-1053.

Aracil, I., Font, R., Conesa, J.A., 2005. Semivolatile and volatile compounds from the pyrolysis and combustion of polyvinyl chloride. Journal of Analytical and Applied Pyrolysis 74, 465-478. 
Barontini, F., Cozzani, V., Marsanich, K., Raffa, V., Petarca, L., 2004. An experimental investigation of tetrabromobisphenol A decomposition pathways. J. Anal. Appl. Pyrol. 72, 41-53.

Birnbaum, L.S., Staskal, D.F., 2004. Brominated flame retardants: cause for concern? Environ. Health Perspect. 112.

Brebu, M., Bhaskar, T., Muto, A., Sakata, Y., 2006. Alkaline hydrothermal treatment of brominated high impact polystyrene (HIPS-Br) for bromine and bromine-free plastic recovery. Chemosphere 64, 1021-1025.

Buekens, A., Yang, J., 2014. Recycling of WEEE plastics: a review. J. Mater. Cycles Waste Manage. $16,415-434$.

Caballero, J.A., Conesa, J.A., 2005. Mathematical considerations for nonisothermal kinetics in thermal decomposition. Journal of Analytical and Applied Pyrolysis 73, 85-100.

Conesa, J.A., Font, R., Fullana, A., Martín-Gullón, I., Aracil, I., Gálvez, A., Moltó, J., Gómez-Rico, M.F., 2009. Comparison between emissions from the pyrolysis and combustion of different wastes. Journal of Analytical and Applied Pyrolysis 84, 95-102.

Conesa, J.A., Rey, L., 2015. Thermogravimetric and kinetic analysis of the decomposition of solid recovered fuel from municipal solid waste. J. Therm. Anal. Calorim. 120, 1233.

Conesa, J.A., Soler, A., 2016. Decomposition kinetics of materials combining biomass and electronic waste. J. Therm. Anal. Calorim., 1-9.

Chien, Y.C., Paul Wang, H., Lin, K.S., Huang, Y.J., Yang, Y.W., 2000. Fate of bromine in pyrolysis of printed circuit board wastes. Chemosphere 40, 383-387.

Das, A., Vidyadhar, A., Mehrotra, S.P., 2009. A novel flowsheet for the recovery of metal values from waste printed circuit boards. Resour. Conserv. Recy. 53, 464-469.

ECS, 2010. Solid biofuels - Determination of ash content. in: ECS (Ed.). European Committee for Standardization.

European Commission, 2000. Directive 2000/76/EC of the European Parliament and of the Council of 4 December 2000 on the incineration of waste. in: European Commission (Ed.), DOUE L 33291 111, pp. 91 - 111.

European Commission, 2012. Directive 2012/19/UE of the European Parliament and of the Council on waste electrical and electronic equipment (WEEE) (recast). in: European Commission (Ed.). Official Journal of the European Commission. European Commission, Brussels, pp. 38-71.

European Council, 2004. Regulation (EC) $\mathrm{N}^{\circ}$ 850/2004 of the European Parliament and of the Council of 29 April 2004 on Persistent Organic Pollutants and amending Directive 79/117/EEC. in: European Council (Ed.), DOUE L 158 7-49, pp. 7-49.

Goosey, M., Kellner, R., 2002. A scoping study: End-of-Life printed circuit boards. Department of Trade and Industry, Intellect \& Shipley Europe Limited, London.

Goosey, M., Kellner, R., 2003. Recycling technologies for the treatment of end of life printed circuit boards (PCBs). Circuit World 29, 33-37.

Guo, J., Guo, J., Xu, Z., 2009. Recycling of non-metallic fractions from waste printed circuit boards: A review. J. Hazard. Mater. 168, 567-590.

Herat, S., 2008. Environmental impacts and use of brominated flame retardants in electrical and electronic equipment. Environmentalist 28, 348-357.

Jaiswal, A., Samuel, C., Patel, B.S., Kumar, M., 2015. Go green with WEEE: Eco-friendly approach for handling e-waste. Procedia Computer Science, pp. 1317-1324.

Kikuchi, S., Kawauchi, K., Ooki, S., Kurosawa, M., Honjho, H., Yagishita, T., 2004. Nondestructive rapid analysis of brominated flame retardants in electrical and electronic equipment using Raman spectroscopy. Anal. Sci. 20, 1111-1112.

Leung, A.O.W., Duzgoren-Aydin, N.S., Cheung, K.C., Wong, M.H., 2008. Heavy metals concentrations of surface dust from e-waste recycling and its human health implications in southeast China. Environ. Sci. Technol. 42, 2674-2680. 
Malkoske, T., Tang, Y., Xu, W., Yu, S., Wang, H., 2016. A review of the environmental distribution, fate, and control of tetrabromobisphenol A released from sources. Sci. Total Environ. 569-570, 1608-1617.

Moltó, J., Egea, S., Conesa, J.A., Font, R., 2011. Thermal decomposition of electronic wastes: Mobile phone case and other parts. Waste Manage. (Oxford) 31, 2546-2552.

NEMA, 2011. NEMA Grade Laminates.

O'Grady, A., Dennis, A.C., Denvir, D., McGarvey, J.J., Bell, S.E.J., 2001. Quantitative Raman Spectroscopy of Highly Fluorescent Samples Using Pseudosecond Derivatives and Multivariate Analysis. Anal. Chem. 73, 2058-2065.

Onwudili, J.A., Williams, P.T., 2009. Degradation of brominated flame-retarded plastics (Br-ABS and Br-HIPS) in supercritical water. J. Supercrit. Fluids 49, 356-368.

Ortuño, N., Conesa, J.A., Molto, J., Font, R., 2014a. Pollutant emissions during pyrolysis and combustion of waste printed circuit boards, before and after metal removal. Sci. Total Environ. 499, 27-35.

Ortuño, N., Conesa, J.A., Moltó, J., Font, R., 2014b. Pollutant emissions during pyrolysis and combustion of waste printed circuit boards, before and after metal removal. Sci. Total Environ. 499, 27-35.

Ortuño, N., Moltó, J., Conesa, J.A., Font, R., 2014c. Formation of brominated pollutants during the pyrolysis and combustion of tetrabromobisphenol A at different temperatures. Environ. Pollut. 191, 31-37.

Ortuño, N., Moltó, J., Egea, S., Font, R., Conesa, J.A., 2013. Thermogravimetric study of the decomposition of printed circuit boards from mobile phones. Journal of Analytical and Applied Pyrolysis.

Owens, C.V., Lambright, C., Bobseine, K., Ryan, B., Gray, L.E., Gullett, B.K., Wilson, V.S., 2007. Identification of Estrogenic Compounds Emitted from the Combustion of Computer Printed Circuit Boards in Electronic Waste. Environ. Sci. Technol. 41, 8506-8511.

Saeed, A., Dlugogorski, B.Z., Altarawneh, M., 2016. Formation of PBDD/F precursors in gas-phase decomposition of tetrabromobisphenol A (TBBA). Organohalogen Compd. 78, 672-676.

Sakai, S.I., Watanabe, J., Honda, Y., Takatsuki, H., Aoki, I., Futamatsu, M., Shiozaki, K., 2001. Combustion of brominated flame retardants and behavior of its byproducts. Chemosphere 42, 519531.

Taurino, R., Pozzi, P., Zanasi, T., 2010. Facile characterization of polymer fractions from waste electrical and electronic equipment (WEEE) for mechanical recycling. Waste Manage. 30, 26012607.

Thomas, S., Wornat, M.J., 2008. The effects of oxygen on the yields of polycyclic aromatic hydrocarbons formed during the pyrolysis and fuel-rich oxidation of catechol. Fuel 87, 768-781.

US EPA, 1994a. Method 26. Determination of hydrogen halide and halogen emissions from stationary sources. Non-isokinetic method. in: US EPA (Ed.). SW-846. United States Environmental Protection Agency, Emissions Measurement Center, Washington, D.C.

US EPA, 1994b. Method 5050. Bomb preparation method for solid waste. in: US EPA (Ed.). SW846. United States Environmental Protection Agency, Office of Solid Waste, Washington, D.C.

US EPA, 1998. Handbook for air toxic emission inventory development. Volume I: Stationary sources. in: US EPA (Ed.). EPA-454/B-98-002. United States Environmental Protection Agency, Office of Air Quality Planning and Standards.

US EPA, 2000a. Method 3545A. Pressurized fluid extraction (PFE). in: US EPA (Ed.). SW-846. United States Environmental Protection Agency, Office of Solid Waste, Washington, D.C.

US EPA, 2000b. Method 9056A. Determination of inorganic anions by ion chromatography. in: US EPA (Ed.). SW-846. United States Environmental Protection Agency, Office of Solid Waste, Washington, D.C. 
US EPA, 2007. Method 8270D. Semivolatile organic compounds by GC/MS. in: US EPA (Ed.). SW-846. United States Environmental Protection Agency, Office of Solid Waste, Washington, D.C. Wang, Y., Zhang, F.S., 2012. Degradation of brominated flame retardant in computer housing plastic by supercritical fluids. J. Hazard. Mater. 205-206, 156-163.

Wath, S.B., Katariya, M.N., Singh, S.K., Kanade, G.S., Vaidya, A.N., 2015. Separation of WPCBs by dissolution of brominated epoxy resins using DMSO and NMP: A comparative study. Chem. Eng. J. 280, 391-398.

Williams, P., 2010. Valorization of Printed Circuit Boards from Waste Electrical and Electronic Equipment by Pyrolysis. Waste and Biomass Valorization 1, 107-120.

Xing, M., Zhang, F.S., 2013. Degradation of brominated epoxy resin and metal recovery from waste printed circuit boards through batch sub/supercritical water treatments. Chem. Eng. J. 219, 131-136.

Yin, J., Li, G., He, W., Huang, J., Xu, M., 2011. Hydrothermal decomposition of brominated epoxy resin in waste printed circuit boards. J. Anal. Appl. Pyrol. 92, 131-136.

Zheng, X., Fu, W., Albin, S., Wise, K.L., Javey, A., Cooper, J.B., 2001. Self-Referencing Raman Probes for Quantitative Analysis. Appl. Spectrosc. 55, 382-388.

Zhou, X., Guo, J., Lin, K., Huang, K., Deng, J., 2013. Leaching characteristics of heavy metals and brominated flame retardants from waste printed circuit boards. J. Hazard. Mater. 246-247, 96-102. 


\section{FIGURE CAPTIONS AND TABLE LEGENDS}

Table 1. Results of debromination experiments.

Table 2. Emission of inorganic bromine during pyrolysis at $850^{\circ} \mathrm{C}$ of the different materials.

Table 3. Emission of brominated compounds during pyrolysis at $850{ }^{\circ} \mathrm{C}$ of the different materials.

Table 4. Balance of bromine.

Figure 1. Thermal decomposition of PCB and the solid products of debromination at the different temperatures studied, in nitrogen at 5,10 and $20{ }^{\circ} \mathrm{C} / \mathrm{min}$.

Figure 2. Thermal decomposition of PCB and the solid products of debromination at the different temperatures studied, in air at 5,10 and $20^{\circ} \mathrm{C} / \mathrm{min}$.

Figure 3. Comparison of the thermal decomposition of PCB and the solid products of debromination at the different temperatures studied, in nitrogen and air at $5{ }^{\circ} \mathrm{C} / \mathrm{min}$.

Figure 4. Emission of PAHs during the pyrolysis at $850{ }^{\circ} \mathrm{C}$ of the different materials.

Figure 5. Emission of semivolatile compounds during the pyrolysis at $850{ }^{\circ} \mathrm{C}$ of the different materials.

Table SM1. Emission of PAHs during pyrolysis at $850{ }^{\circ} \mathrm{C}$ of the different materials.

Figure SM1. Raman spectra of (a) TBBPA and (b) PCB.

Figure SM2. Elemental analysis of the solid samples prepared. 